\title{
Techno-Economic Comparison of Operational Aspects for Direct Drive and Gearbox-Driven Wind Turbines
}

\author{
David McMillan, Member, IEEE, and Graham W. Ault, Member, IEEE
}

\begin{abstract}
The majority of wind turbines currently in operation have the conventional Danish concept design-that is, the threebladed rotor of such turbines is indirectly coupled with an electrical generator via a gearbox. Recent technological developments have enabled direct drive wind turbines to become economically feasible. Potentially, direct drive wind turbines may enjoy higher levels of availability due to the removal of the gearbox from the design. However, this is only a theory: so far not substantiated by detailed analytic calculation. By providing such a calculation, this paper enables us to quantitatively evaluate technical and economic merits of direct drive and gearbox-driven wind turbines.
\end{abstract}

Index Terms-Markov chain, operational comparison, reliability, wind turbines.

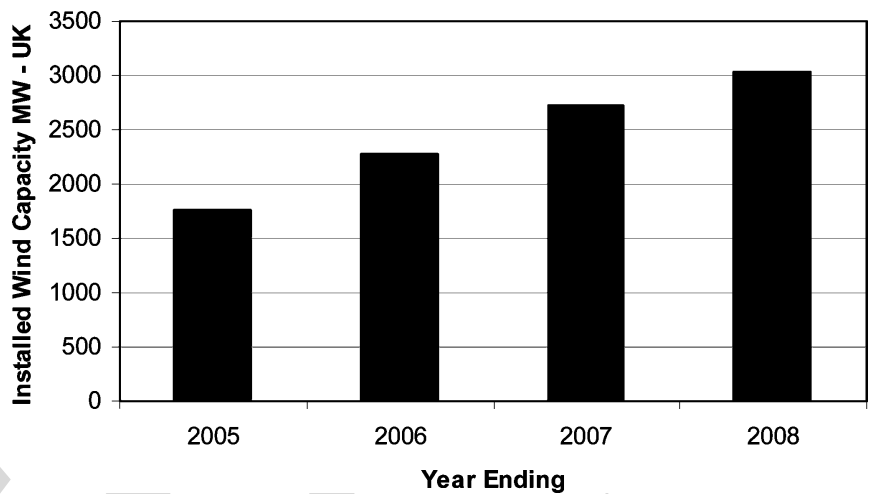

Fig. 1. Recent growth in U.K. wind generation capacity [2].

machines. This analysis is based on quantitative modeling of the operation, failure, and maintenance of wind turbine units as proposed in [5]. Such an operational comparison of different wind turbine concepts is not available in the existing literature.

\section{COMPARISON OF CONCEPTS}

\section{A. Conventional Danish Concept-Gearbox Driven}

The conventional Danish concept comprises a three-bladed upwind rotor, which revolves on the horizontal axis (sometimes called horizontal axis wind turbine, HAWT). The coupling between rotor and electrical generator is indirect and is achieved via a gearbox in order to increase the rotational speed to a level that can drive a relatively small-diameter, lightweight induction generator. A conceptual view of the energy conversion process for such a typical modern wind turbine is outlined in Fig. 2.

The whole wind turbine assembly rotates into the prevalent wind direction on its vertical axis by means of an electromechanical yaw system. Once facing into the wind, control of the mechanical input power is achieved either by aerodynamic design of the rotor (stall control) or by actively changing the angle of attack of the rotor blades to the wind (pitch control) via electrical motors or hydraulics.

The electrical configuration of Danish concept WTs is influenced by mechanical aspects, as one main objective of the WT mechanical design is to minimize the weight at the top of the tower, where the nacelle (containing the generator) is located in modern HAWTs. This means the generator has to be as light as possible and must have a relatively small physical footprint. For this reason, induction generators are employed: induction generators have the added advantage of being more robust than 


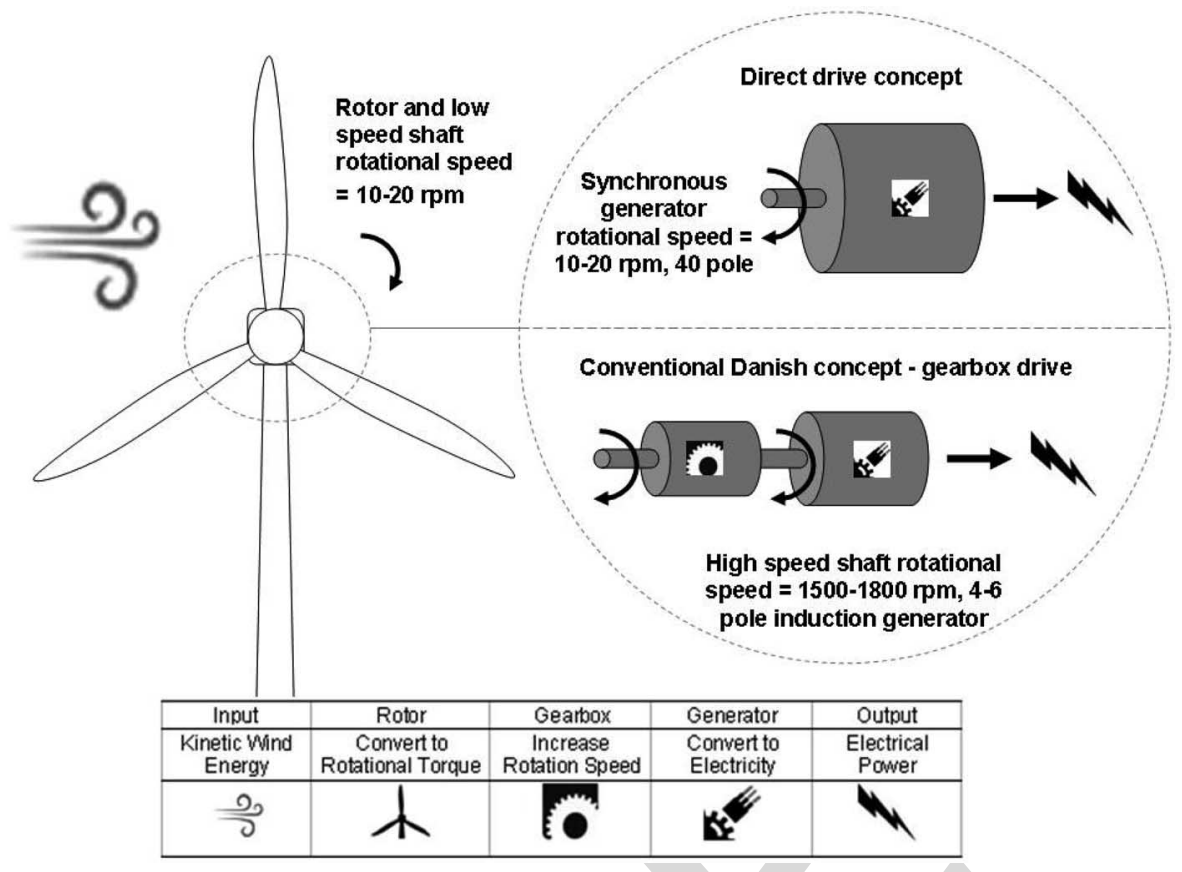

Fig. 2. Process diagram for gearbox-driven and direct drive wind turbines.

synchronous generators and tend to have fewer electrical faults. However, due to the low rotational speed of the wind turbine rotor, a gearbox has to be used to increase the rotation from tens of revolutions per minute at the gearbox input to thousands at the output. The primary reason for this is the low number of induction generator poles.

The older Danish concept WTs that operated at fixed speed employed squirrel cage induction generators; however, newer variable speed technology has resulted in a switch to doubly fed induction generators (DFIG), which are now the dominant wind turbine generator configuration. The reason for the dominance of this configuration is that it represents a good compromise between economy and performance. It is relatively economic because it has only a partial electronic converter rated at $\sim 30 \%$ of the generator output [6], not a full converter.

\section{B. Direct Drive Concept}

In a direct drive WT, the main rotor is coupled to the generator input shaft, eliminating the need for a gearbox in the design. In order to generate power at such a low rotation speed, the generator has to have many pole pairs, and usually a synchronous generator is employed. This implies much greater dimensions and weight as compared with an induction generator. In addition, a fully rated electronic power converter is required, which increases the cost of the system.

\section{Types of Comparison}

There are several examples in the published literature where a comparison is made between the two concepts. For example, Tavner et al. [3] focused on how the configuration of the WT generator and converter in different design concepts affected overall WT reliability. The data utilized by the authors had enough detail to enable a direct reliability comparison of three WT concepts: fixed speed with gearbox, variable speed with gearbox, and variable speed direct drive (no gearbox: synchronous generator). The main conclusion was that direct drive systems are less reliable than models with a gearbox because the potential increase in reliability due to elimination of gearbox failures is cancelled out by increased generator, inverter, and electrical system failures.

Interestingly, the authors recognized that overall availability would also be affected by component repair times: In this sense direct drive systems may have an advantage, as mean time to repair (MTTR) for a gearbox is likely to be very much more than MTTR for an electronics subassembly. As yet, no other research has addressed this operational comparison of the two concepts.

Echavarria et al. [4] analyzed a similar dataset, which provides some highly relevant information regarding the reliability of the two WT concepts. In particular, the data suggest that generator failures in direct drive WTs are roughly two times the gearbox-driven equivalent ( 0.22 failures per annum compared with 0.12 suggested by Tavner $e t$ al. [7]). Similarly, power electronics failures in direct drive synchronous machines are quantified as 1.03 failures per annum compared to 0.661 suggested in [7] for the induction machine equivalent.

Polinder et al. [6] examine direct drive and gearbox-driven WT concepts from the viewpoint of design and economic performance. The authors define a typical Danish concept WT with a three-stage gearbox (3GDFIG) and a direct drive machine coupled to a synchronous generator (DDSG). Three other concepts are also defined (DFIG with a single-stage gearbox, permanent magnet direct drive, and permanent magnet single-stage gearbox) but these are not considered in this paper due to the fact that they are not currently deployed in significant numbers. 


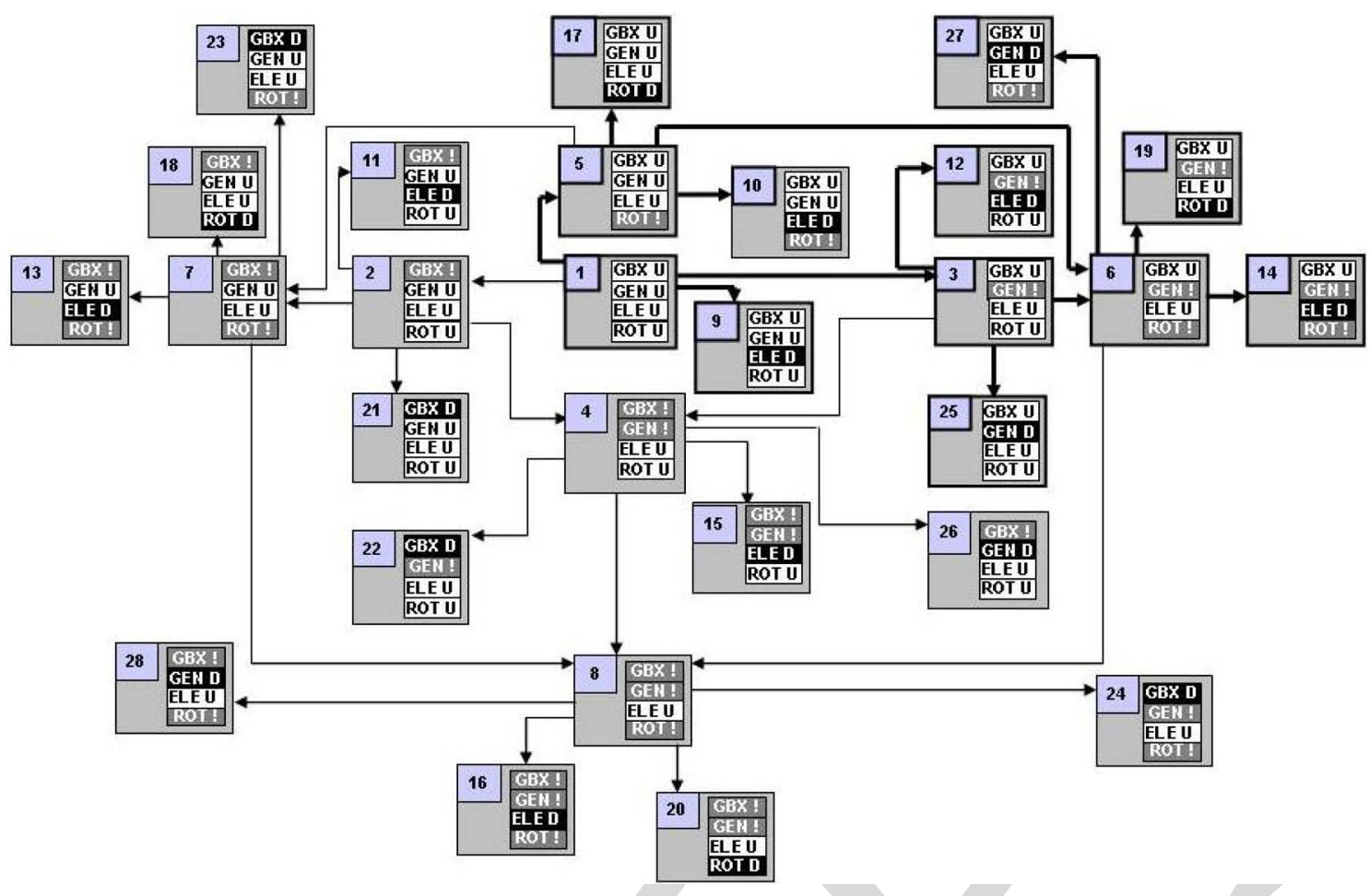

Fig. 3. Markov chain of key wind turbine components. Bold arrows and boxes indicate direct drive system.

The authors again highlight the need for further work to better understand the reliability and availability benefits of adopting different WT design concepts-a requirement which this paper aims to meet.

\section{MOdELING OF Wind TURBINE CONCEPTS}

\section{A. Physical Modeling of Wind Turbine Components}

In order to build an accurate operational model, the key physical components of the WT must be identified and a suitable mathematical representation decided upon. It was reported in [5] that using a combination of failure rate data, downtime estimates, and expert opinion, the key components of a gearboxdriven WT could be identified as follows:

1) gearbox (GBX);

2) generator (GEN);

3) rotor blades (ROT); and

4) inverter, electronics, and control (ELE).

In terms of the mathematical representation, a Markov chain solved via Monte Carlo simulation (MCS) was identified in previous studies as a suitable model framework [5]. The Markov chain representation has been very successfully applied to power systems infrastructure deterioration and failure modeling, including wind turbines [8], [9]. The main problem with these analytically solved models is that the introduction of constraints, such as weather-constrained maintenance, makes obtaining a solution rather difficult. Although not computationally efficient, MCS methods overcome this difficulty and have been applied to similar problems in the past [10], [11]. Since the problem considered is essentially a planning problem, the time required to get the solution is of little importance.
It has been assumed that three states are sufficient to capture the deterioration and failure processes of the GBX, GEN, and ROT. ELE failures are assumed to be instantaneous and, therefore, require only binary representation. When all four components are modeled in a single Markov state-space, the total number of states is 54 . This is cut down to 28 by assuming that degradation and failure events of different WT components cannot happen concurrently. Furthermore, for a GBX, GEN, or ROT failure to occur, the system must transit through the deteriorated (intermediate) state before outright failure.

The possible Markov states and transitions for the overall WT system are visualized in Fig. 3. The three possible deterioration levels are indicated as fully up (U), deteriorated (!), and down (D).

All 28 states and transitions are possible for the case of gearbox-driven WTs. The obvious physical difference when modeling a direct drive WT is that there are no gearbox states. Thus, the bold arrows in Fig. 3 refer to the transitions and states that represent direct drive WTs, as a 12-state subset.

The arrows in Fig. 3 represent transition probabilities (e.g., probability of transition from state $a$ to state $b$ is $p_{a, b}$ ), whose magnitude must be estimated. These probabilities depend only on the current state of the system $(s)$ at current time $t_{k}$. Equation 1 expresses this "memory-less" property of a Markov chain

$$
p_{a, b}=p\left(s_{b}, t_{k+1} \mid s_{a}, t_{k}\right) \quad k=1,2,3, \ldots
$$

Furthermore, the transition probabilities are constant in time: 186 This is the "time-stationary" property. The magnitude of all 187 transition probabilities from one state $(a)$ to all others in the 188 


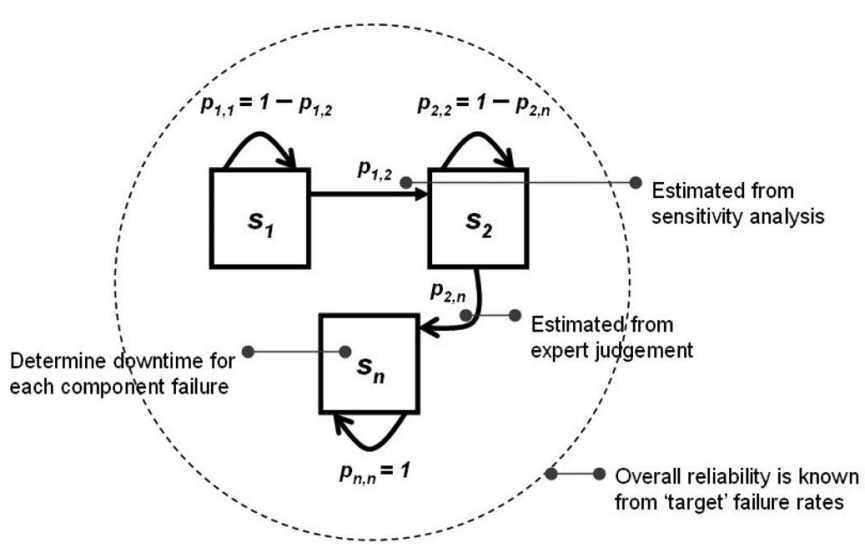

Fig. 4. Parameter estimation for Markov chain.

system must sum to unity. This is shown in (2)

$$
\sum_{b} p_{a, b}=1 \quad a=1 \ldots n
$$

where $n$ is the total number of system states. For convenience, the transition probabilities for the whole system are expressed in a transition probability matrix (TPM). For the case of the system in Fig. 3, the TPM is shown in (3). Note that only the possible transitions (indicated in Fig. 3. with arrows) need to be estimated-all other probabilities are equal to zero

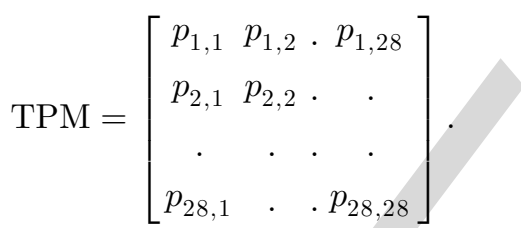

The TPM values are estimated based on the partial information available, as illustrated in Fig. 4. A good estimate of the overall reliability ("target" failure rate) is known from the work of Tavner et al. [7].

Similarly, downtime estimates can be made for the outage of the key components [5]. The probability of an outright failure in a deteriorated condition $\left(p_{2, n}\right)$ can be estimated based on expert opinion of times to failure. The remaining parameters can then be estimated by conducting sensitivity analyses (previously reported in [5]).

\section{B. Data for Physical Model}

The study of Tavner et al. [7] provided estimates of component failure rates based on populations of Danish and German WTs. The German population was larger (over 4,000 machines) and the population consisted of more modern WTs. Therefore, the German figures are used to fit the gearbox-drive WT physical model.

On the other hand, Echavarria et al. [4] suggest modifications to the GEN and ELE failure rates for direct drive machines. Taking this into account, the target failure rates for both WT concepts can be visualized in Fig. 5 .

Downtimes for the failure types are as follows: GBX-30 days, GEN-21 days, ELE-1 day, and ROT - 30 days. They are based on domain knowledge elicited in [5]. Using this

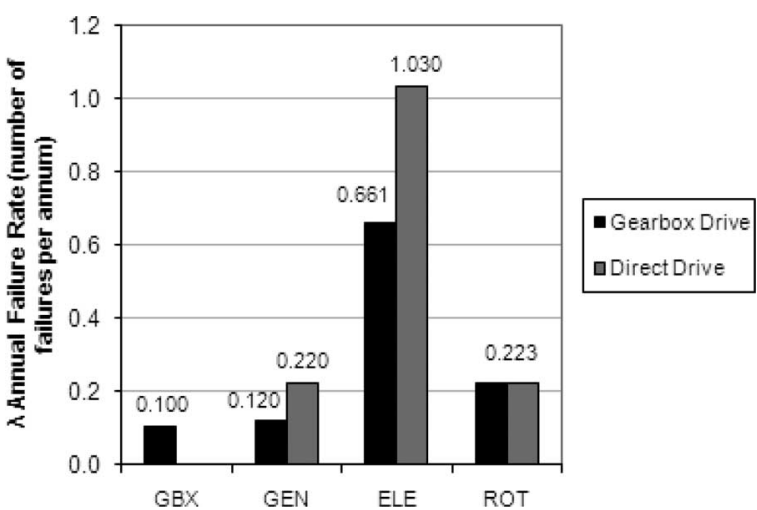

Fig. 5. Reliability for gearbox-driven and direct drive wind turbines.

information, the TPM parameters were estimated based on the 220 iterative procedure devised in [5]. The procedure is based on 221 sensitivity analysis estimation of the unknown parameter $p_{1,2} 222$ (see Fig. 4).

The Markov chain has been defined for both gearbox-driven 224 and direct drive concepts. In the following sections, other as- 225 pects of operational modeling - which are common to both 226 concepts-are discussed.

\section{Energy Yield Modeling}

There are two main components to the energy yield model. 229 These are the wind speed model and the power curve model. The 230 wind speed (WS) model previously used by the authors [5] was 231 based on a single parameter autoregressive process, or AR(1). 232 This is displayed in (4), where $\mu$ is the mean of a wind speed 233 time series, $\phi$ is the autoregressive parameter and the process is 234 driven by a Gaussian white noise function $\varepsilon_{t}$.

$$
\mathrm{WS}_{t}-\mu=\phi\left(\mathrm{WS}_{t-1}-\mu\right)+\varepsilon_{t} .
$$

The dataset used to fit the model was sourced from a su- 236 pervisory control and data acquisition (SCADA) system of a 237 U.K. wind farm. Estimation of $\phi$ and $\varepsilon_{t}$ was achieved by lin- 238 ear least squares, while classification of the model was based 239 on inspection of the autocorrelation and partial-autocorrelation 240 functions.

The power curve model is based on a manufacturers' datasheet for a 2 MW WT [12], which is sampled and the theoretical equation for the power $(P)$ in the wind $(5)$ is matched to the data samples by modeling the coefficient of performance $C_{p}$

$$
P=\frac{1}{2} \rho \pi r^{2} v^{3}\left(\times C_{p}\right) .
$$

In (5), $\rho$ is air density $\left(\mathrm{kg} / \mathrm{m}^{3}\right), r$ is the rotor radius (m), and $v \quad 247$ is air velocity through the WT rotor $(\mathrm{m} / \mathrm{s})$. The re-created power 248 curve is shown in Fig. 6 and has cut in, rated, and cut out wind 249 speeds of 4,14 , and $25 \mathrm{~m} / \mathrm{s}$, respectively. It is assumed that both 250 WT concepts adhere to the same power curve. 


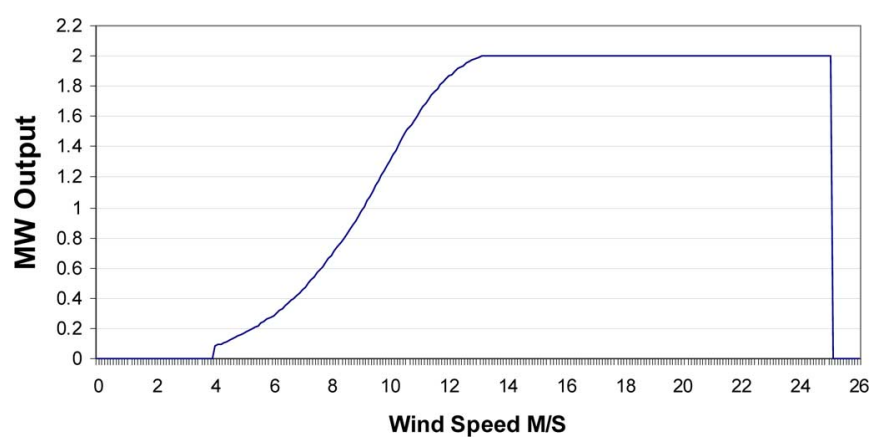

Fig. 6. Power curve for $2 \mathrm{MW}$ wind turbine [12].

\section{Maintenance Modeling}

It is assumed that a six-monthly periodic maintenance plan is adopted for both WT concepts. The assumptions in the maintenance model are that maintenance actions restore the WT to the fully up state (state 1 in Fig. 3) and that each maintenance visit involves a one-day outage. The model can easily accommodate condition-based maintenance (CBM), but since maintenance paradigms are not the focus of this paper, this possibility is neglected.

If a component failure occurs, a maintenance team is dispatched immediately. There is a probability that a component replacement is necessary (replacement factor $\beta=0.6$ ) or that it can be repaired $(1-\beta=0.4)$. This is based on an analysis by Ribrant and Bertling [13] who highlighted that around $60 \%$ of gearbox failures require a replacement rather than a repair action. Similar figures have not been published for the other WT components; therefore, due to the lack of data, they are assumed to have the same probabilities of repair and replacement as the gearbox.

If the component can be repaired, it is restored instantaneously to a functional state. If a replacement is required, downtime lasts as follows: GBX-30 days, GEN-21 days, ELE-1 day, and ROT-30 days. This is based on the experience of a wind farm operator. Furthermore, maintenance actions are constrained by wind speed as in [5]. This means that nacelle-related replacements need wind speed conditions of less than $10 \mathrm{~m} / \mathrm{s}$, while rotor maintenance cannot be conducted in wind speeds over $7 \mathrm{~m} / \mathrm{s}$.

\section{E. Costs and Revenue}

It is of interest to compare the economic merits of the two WT configurations. Therefore, a cost model has been built which generates revenue from energy yield and incurs maintenance and replacement costs.

Polinder et al. provided costs for gearbox-driven and direct drive wind turbine components rated at $3 \mathrm{MW}$ [6]. Figures can be derived for $2 \mathrm{MW}$ machines of both types assuming that the cost varies linearly with the rating. These costs are provided in Table I. The rotor cost was not provided in [6] and so the value derived previously by the authors of this paper is adopted [5]. In the case of a component replacement, the full cost in Table I
TABLE I

COMPONENT COSTS FOR WIND TURBINE CONCEPTS

\begin{tabular}{|c|c|c|}
\hline Component & Cost $£$ & Direct drive \\
\hline GBX & 121,733 & N/A \\
\hline GEN & 177,066 & 313,740 \\
\hline ROT & 210,000 & 210,000 \\
\hline ELE & 22,133 & 66,400 \\
\hline
\end{tabular}

is incurred. In the case of a repair, it is assumed that only $10 \%$ of this cost is incurred (repair cost factor $\alpha=0.1$ ).

Besides the costs of the components themselves, the cost of labor and equipment hire has been included. Andrawus [14] showed that skilled labor for WT repairs costs around $£ 50 / \mathrm{h}$. It has been assumed that three crew working an $8 \mathrm{~h}$ shift constitute one maintenance action. Therefore, the cost of labor $\left(C_{\mathrm{LAB}}\right)$ is $£ 1200$ per action. Similarly, hire rates for telescopic cranes $\left(C_{\mathrm{EQ}}\right)$ needed to perform nacelle component lifting operations have been quantified by industry sources [15] as $£ 1500$ per week. Lost revenue due to downtime is also taken into account $\left(R_{\mathrm{LOST}}\right)$ - this is wind speed-dependent. These costs are combined with the component costs (see Table I) to calculate replacement (6), repair, (7) and O\&M cost (8)

$$
\begin{aligned}
C_{\text {replace }} & =\beta \lambda\left(C_{\mathrm{CAP}}+C_{\mathrm{LAB}}+C_{\mathrm{EQ}}+R_{\mathrm{LOST}}\right) \\
C_{\text {repair }} & =(1-\beta) \lambda \times\left(\alpha C_{\mathrm{CAP}}+C_{\mathrm{LAB}}+C_{\mathrm{EQ}}+R_{\mathrm{LOST}}\right) \\
C_{\mathrm{O} \& \mathrm{M}} & =C_{\text {replace }}+C_{\text {repair }} .
\end{aligned}
$$

The revenue model for the WT is based on the energy yield in each one-day simulation interval. Using equations (4) and (5), this energy yield $Y$ can be calculated as the power (see Fig. 6) multiplied by a time interval $\Delta t$. The energy yielded in a year is then calculated by summing the output over all individual days in the year.

The revenue stream $R$ can then be calculated by applying equation (9). MP represents the market price for electricity and renewable obligation certificates (ROCs). For this paper, $\mathrm{MP}_{\text {elec }}$ and $\mathrm{MP}_{\mathrm{ROC}}$ are set to $£ 36$ and $£ 40$ per MWh, respectively. Although in reality, electricity and ROC prices fluctuate, the annual mean is adequately represented by the figures presented as

$$
R=Y\left(\mathrm{MP}_{\text {elec }}+\mathrm{MP}_{\mathrm{ROC}}\right)-C_{\mathrm{O} \& \mathrm{M}} .
$$

It is important to note that any differences in yield between the two WT concepts will be related to the reliability and downtime (see Fig. 5 and Section III-D) of the two WT concepts, rather than to the differences in the electrical design. This is because the same power curve (Fig. 6) has been used for both WT concepts.

Polinder et al. showed that the theoretical difference in yield between a $3 \mathrm{MW}$ direct drive machine (DDSG) and a typical 3 MW DFIG (DFIG3G) is $+150 \mathrm{MWh}$ [6], if the detail of the electrical machine design is taken into account. Assuming this difference scales linearly with WT rating, it means that for the $2 \mathrm{MW}$ machines considered in this paper, the direct drive machine yields roughly $100 \mathrm{MWh}$ more per annum than the 


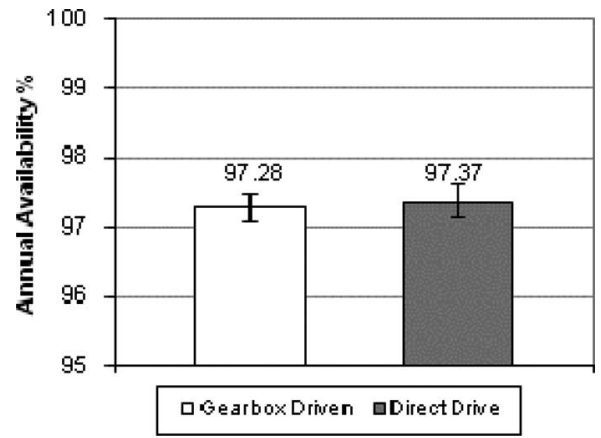

Fig. 7. Availability comparison of wind turbine concepts.

DFIG. Applying (9) and neglecting the O\&M cost, this translates to $£ 7600$ more revenue per annum for the direct drive machine. Therefore, the annual revenue for the direct drive machine has been boosted by $£ 7600$ per annum in the studies that follow.

\section{F. Program Operation}

The models outlined in this section were coded in FORTRAN 95, with the SCADA database interface for the wind speed model written using f90SQL [16]. The statistical programming language $\mathrm{R}$ was used to fit the wind speed model defined in (4). The resultant capacity factor of the wind turbine based on the simulated wind speed and power curve is just under $30 \%$.

The confidence limit $L$ of the simulation results can be measured by applying (10). Taking the Student- $t$ distribution, and setting the level of confidence to $95 \%$, it means that $L$ can be specified, provided that the number of samples $(N)$ and standard deviation $(\sigma)$ of the quantity are known. $L$ is shown in the results as confidence bands that specify the accuracy of the results

$$
L= \pm \frac{2.045 \times \sigma}{\sqrt{N}} .
$$

\section{A. Operational Comparison of Concepts}

Two comparisons are made in order to benchmark the operational merits of the two WT concepts: a technical comparison and an economic comparison. The first result in Fig. 7 compares the overall availability of the two concepts.

It can be seen that despite removing the gearbox from the design, the direct drive concept has similar overall availability to the gearbox-driven machine. Although the availability is marginally better for the case of the direct drive machine, the confidence limits show that this technical benefit is uncertain. It should be noted that grid availability is not included in this paper.

The second result, displayed in Fig. 8, shows the revenue generated (9) for both concepts. This shows that the gearboxdriven design has a much larger economic benefit than the direct drive concept.

The contribution to the revenue of increased energy yield due to avoidance of downtime is negligible in the case of Fig. 8 (direct drive machine avoids loss of $\sim 6.35 \mathrm{MWh}$ more energy

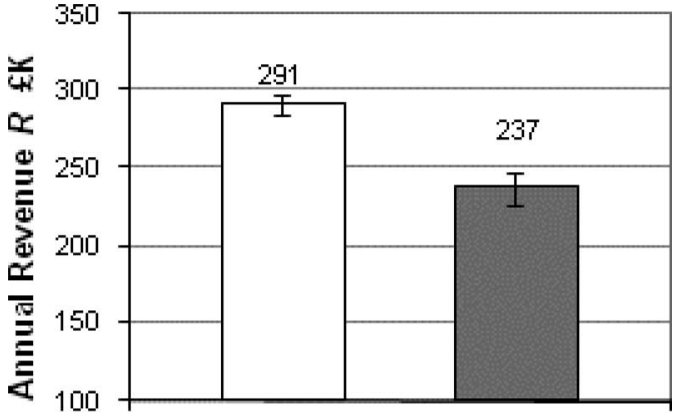

口b̀earboxDriwen aDirect Driwe

Fig. 8. Economic comparison of wind turbine concepts.

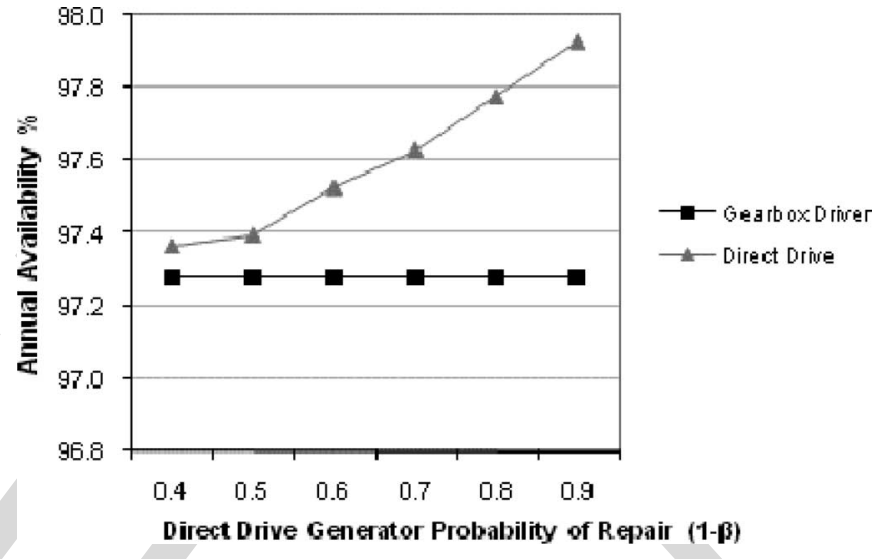

Fig. 9. Availability improvement of direct drive wind turbine as a function of generator reparability.

than gearbox-driven, economic benefit $=£ 482$ per annum). 368 Therefore, the large disparity in revenue $(\sim £ 44000$ per annum) 369 must be due to incurred repair and replacement costs. The large 370 increase in cost and failure rate for the generator in particular 371 (see Table I and Fig. 5) appears to economically handicap the 372 direct drive concept.

\section{B. Operational Impact of Generator Reparability}

One possible explanation of the superior economic performance of the gearbox-drive concept is that a replacement factor $(\beta)$ of 0.6 per failure (see Section III-D) may represent a pessimistic view of the "reparability" of a WT synchronous generator. Indeed, it has been reported elsewhere [3] that the increase in generator failure rate for the direct drive concept is related to electrical failures rather than mechanical failures. Electrical faults will be less likely to involve a complete component replacement; therefore, the robustness of the conclusion drawn from Fig. 8 is tested by modeling different levels of reparability for the direct drive generator.

The replacement factor $\beta$ was reduced from the base value of 386 $0.6-0.1$, as shown in Fig. 9. This figure shows that the opera- 387 tional availability of the direct drive concept WT can be signif- 388 icantly higher than the gearbox-driven WT, if a high proportion 389 of synchronous generator failures are minor electrical failures 390 rather than severe mechanical failures (e.g., bearing problems). 391 


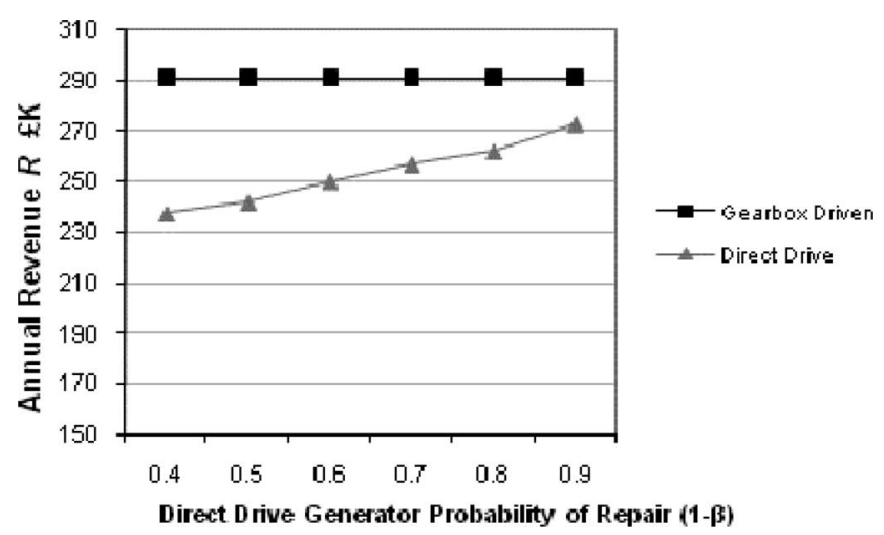

Fig. 10. Revenue increase of direct drive wind turbine as a function of generator reparability.

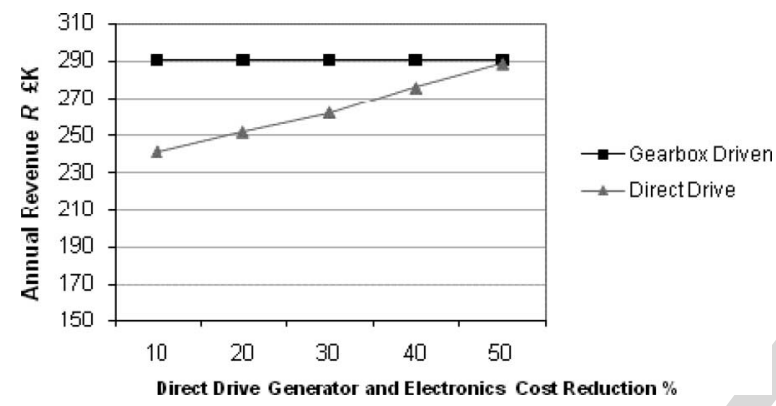

Fig. 11. Revenue increase of direct drive wind turbine as a function of component cost reduction.

The final result shows that if substantial cost reductions in direct drive technology are achieved in the future, this measure may be enough to make the technology cost-competitive with DFIGs. However, very large cost reductions of $50 \%+$ will be required. At current prices, the economic argument for a switch to direct drive technology, for the onshore conditions evaluated, appears to be weak.

\section{CONCLUSION}

An operational comparison of direct drive and gearbox-driven wind turbines has been presented in this paper. The results suggest that there may be a technical advantage in deploying direct drive machines over more established gearbox-driven designs (see Fig. 9). In all cases, the economic analysis shows that gearbox-driven machines are still preferable, unless manufacturing costs of direct drive technology can be significantly reduced (see Fig. 11).

There are some issues that need to be better understood in order to make more precise comparisons of these technologies. One is that the repair probability of the components needs to be investigated, in a manner similar to the one presented in [13] but for all WT components. The failure rate increase for a synchronous generator relative to an induction generator (reported in [3], [4]) will be made up mainly of electrical-related failures rather than mechanical failures. It would be interesting to see what proportion of direct drive WT generator failures are low downtime (e.g., 1-3 days) as opposed to a mechanical failure of a rotating component, which in some cases could take as long as 60 days to replace [14]. Such an analysis would aid understanding of WT failure modes and make operational comparisons more accurate.

This study was carried out for fairly typical onshore conditions, but the conclusions may be linked to the site conditions. Direct drive machines are perceived by some manufacturers as primarily an offshore technology [18]. By modeling the offshore wind resource, logistics, increased downtimes, and offshore access constraints, it may be possible to determine if direct drive machines would become more economically attractive in offshore conditions than the analysis presented in this paper shows. The conclusions of the results in this paper and any further analysis as described will be of value to both manufacturers and operators of wind turbines.

\section{ACKNOWLEDGMENT}

The authors would like to thank Y. Patel of Scottish Power/Iberdrola and M. Smith of Macom Technologies for their valuable input to this paper. The authors would also like to thank Dr. D. Hill and the IEEE reviewer for their valuable comments.

\section{REFERENCES}

[1] Scottish Power/Iberdrola press release (2008, Nov. 9). "Scottish Power Renewables Windfarm Pushes Britain Past 3GW Wind Energy Landmark," [Online]. Available: http://www.(scottishpower.com/ PressReleases_1774.htm)

[2] British Wind Energy Association (2008, Nov. 15). "Operational wind farms," [Online]. Available: http://www.(bwea.com/ukwed/ 470 operational.asp) 
[3] P. J. Tavner, G. J. W. V. Bussel, and F. Spinato, "Machine and converter reliabilities in wind turbines," in Proc. 3rd Power Electron. Mach. Drives Conf. (PEMD 2006), Cork, Ireland, Mar., pp. 127-130.

[4] E. Echavarria, B. Hahn, G. J. W. van Bussel, and T. Tomiyama, "Reliability of wind turbine technology through time," Trans. ASME (J. Sol. Eng.), vol. 130, no. 3, pp. 0310051-0310058, Aug. 2008.

[5] D. McMillan and G. W. Ault, "Condition monitoring benefit for wind turbines: Sensitivity to operational parameters," IET Renewable Power Generation, vol. 2, no. 1, pp. 60-72, Mar. 2008.

[6] H. Polinder, F. F. A. Van Der Pijl, G. de Vilder, and P. J. Tavner, "Comparison of direct-drive and geared generator concepts for wind turbines,' IEEE Trans. Energy Convers., vol. 21, no. 3, pp. 725-733, Sep. 2006.

[7] P. J. Tavner, J. Xiang, and F. Spinato, "Reliability analysis for wind turbines," Wind Energy, vol. 10, no. 1, pp. 1-18, Jun. 2007.

[8] R. P. Hoskins, G. Strbac, and A. T. Brint, "Modelling the degradation of condition indices," IEE Proc.- Generation, Transmiss., Distrib., vol. 146, no. 4, pp. 386-392, Jul. 2002.

[9] F. C. Sayas and R. N. Allan, "Generation availability assessment of wind farms," IEE Proc.- Generation, Transmiss., Distrib., vol. 143, no. 5, pp. 507-518, Sep. 1996.

[10] M. Marseguerra, E. Zio, and L. Podofillini, "Condition-based maintenance optimization by means of genetic algorithms and Monte Carlo simulation,' Rel. Eng. Syst. Safety, vol. 77, no. 2, pp. 151-165, Jul. 2002.

11] N. B. Negra, O. Holmstrom, B. Bak-Jensen, and P. Sorensen, "Aspects of relevance in offshore wind farm reliability assessment," IEEE Trans. Energy Convers., vol. 22, no. 1, pp. 159-166, Mar. 2007.

[12] Vestas (2008, May 1). "V80-2.0 MW Versatile Megawattage," Manufacturers Data Sheet. [Online]. Available: http://www.vestas.com/en/windpower-solutions/wind-turbines/2.0-mw.aspx

[13] J. Ribrant and L. Bertling, "Survey of failures in wind power systems with focus on Swedish wind power plants during 1997-2005," IEEE Trans. Energy Convers., vol. 22, no. 1, pp. 167-173, Mar. 2007.

14] J. A. Andrawus, J. Watson, M. Kishk, and A. Adam, "The selection of a suitable maintenance strategy for wind turbines," Wind Eng., vol. 30, no. 6, pp. 471-486, Dec. 2006.

[15] Anon "Expansion based on rental," Cranes Access, vol. 8, no. 7, pp. 2425, Oct. 2006.

[16] F90SQL, [Online]. Available: http://www.(http://www.canaimasoft.com/ f90sql/)

[17] Enercon GmbH E-82 2008, Dec. 1). [Online]. Available: http:// www.(http://www.enercon.de/en/ home.htm)

[18] K. Larsen, "Making wind more efficient," Renew. Energy Focus, pp. 4042, Nov./Dec. 2008

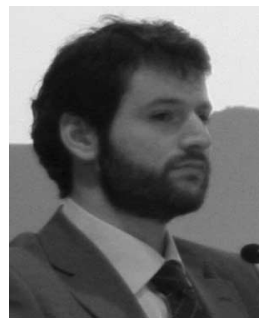

David McMillan (M'06) received the B.Eng. de- 515 gree in electronics and electrical engineering from the 516 University of Glasgow, Glasgow, Scotland, U.K., in 517 2002, and the M.Sc. and Ph.D. degrees from the Uni- 518 versity of Strathclyde, Glasgow, in 2005 and 2008, 519 respectively.

From 2002 to 2004, he was a Manufacturing En- 521 gineer with Methode Electronics, Burnley. He is cur- 522 rently a Research Fellow at the Institute for Energy 523 and Environment, University of Strathclyde. His re- 524 search interests include techno-economic analysis of 525 energy generation and infrastructure and storage technologies.

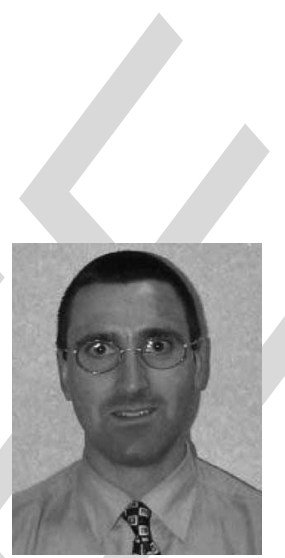

Graham W. Ault (S'96-M'00) received the B.Eng. degree in electrical and mechanical engineering, and 529 the $\mathrm{Ph} . \mathrm{D}$. degree in electrical power systems from the 530 University of Strathclyde, Glasgow, Scotland, U.K., 531 in 1993 and 2000, respectively.

$\mathrm{He}$ is currently a Reader with the University of 533 Strathclyde, where he has been engaged in several 534 aspects of distributed and renewable generation, asset 535 management, and power system planning and devel- 536 opment. He has been actively involved in national and 537 international initiatives to advance the development 538 of the renewable energy industry through the Institution of Engineering and 539 Technology, IEEE, Congrès International des Réseaux Electriques de Distribu- 540 tion or International Conference on Electricity Distribution, and International 541 Energy Agency. 
Q1: Author: Please check the edit changes in this sentence for correctness.

Q2. Author: Please check the edit changes in this sentence for correctness.

Q3. Author: Please provide year in Ref. [16].

Q4. Author: Please provide complete bibliographic details in Ref. [18]. 


\title{
Techno-Economic Comparison of Operational Aspects for Direct Drive and Gearbox-Driven Wind Turbines
}

\author{
David McMillan, Member, IEEE, and Graham W. Ault, Member, IEEE
}

\begin{abstract}
The majority of wind turbines currently in operation have the conventional Danish concept design-that is, the threebladed rotor of such turbines is indirectly coupled with an electrical generator via a gearbox. Recent technological developments have enabled direct drive wind turbines to become economically feasible. Potentially, direct drive wind turbines may enjoy higher levels of availability due to the removal of the gearbox from the design. However, this is only a theory: so far not substantiated by detailed analytic calculation. By providing such a calculation, this paper enables us to quantitatively evaluate technical and economic merits of direct drive and gearbox-driven wind turbines.
\end{abstract}

Index Terms-Markov chain, operational comparison, reliability, wind turbines.

\section{INTRODUCTION}

W ORLDWIDE installed capacity of wind generation is growing significantly and is likely to continue to increase in the future. The twin policy objectives of energy security and climate change mitigation have resulted in economic incentives, which in turn, have driven investment in wind energy. Taking the U.K. as an example, Fig. 1 shows how the installed capacity has grown since 2005-by the end of 2008, the installed capacity broke through the $3 \mathrm{GW}$ barrier [1]. This $3 \mathrm{GW}$ capacity consists of 2276 individual wind turbines (WTs) [2], the vast majority of which are conventional Danish concept, gearboxdriven machines. However, recent technical strides have enabled direct drive machines to become economically feasible.

Since a gearbox is not included in the direct drive concept, it is clear that the reliability and availability of the WT will improve-if it can be assumed that all other factors remain unchanged. On the other hand, it has been reported in the paper that failure rates of electrical components and generators of direct drive wind turbines are significantly higher than those of gearbox-driven equivalents [3], [4]. The purpose of this paper is to establish if there is a technical and/ or economic advantage in deploying direct drive wind turbines instead of gearbox-driven

Manuscript received December 5, 2008; revised. This work was fully supported by the United Kingdom Engineering and Physical Sciences Research Council under the Prosen project Grant EP/C547594/1. Paper no. TEC-004832008.

D. McMillan is with the Institute for Energy and Environment, University of Strathclyde, Glasgow G1 1XQ, Scotland, U.K. (e-mail: dmcmillan@ eee.strath.ac.uk).

G. W. Ault is with the University of Strathclyde, Glasgow G1 1XQ, Scotland, U.K. (e-mail: dmcmillan@eee.strath.ac.uk).

Color versions of one or more of the figures in this paper are available online at http://ieeexplore.ieee.org.

Digital Object Identifier 10.1109/TEC.2009.2032596



Fig. 1. Recent growth in U.K. wind generation capacity [2].

machines. This analysis is based on quantitative modeling of the operation, failure, and maintenance of wind turbine units as proposed in [5]. Such an operational comparison of different wind turbine concepts is not available in the existing literature.

\section{COMPARISON OF CONCEPTS}

\section{A. Conventional Danish Concept-Gearbox Driven}

The conventional Danish concept comprises a three-bladed upwind rotor, which revolves on the horizontal axis (sometimes called horizontal axis wind turbine, HAWT). The coupling between rotor and electrical generator is indirect and is achieved via a gearbox in order to increase the rotational speed to a level that can drive a relatively small-diameter, lightweight induction generator. A conceptual view of the energy conversion process for such a typical modern wind turbine is outlined in Fig. 2.

The whole wind turbine assembly rotates into the prevalent wind direction on its vertical axis by means of an electromechanical yaw system. Once facing into the wind, control of the mechanical input power is achieved either by aerodynamic design of the rotor (stall control) or by actively changing the angle of attack of the rotor blades to the wind (pitch control) via electrical motors or hydraulics.

The electrical configuration of Danish concept WTs is influenced by mechanical aspects, as one main objective of the WT mechanical design is to minimize the weight at the top of the tower, where the nacelle (containing the generator) is located in modern HAWTs. This means the generator has to be as light as possible and must have a relatively small physical footprint. For this reason, induction generators are employed: induction generators have the added advantage of being more robust than 


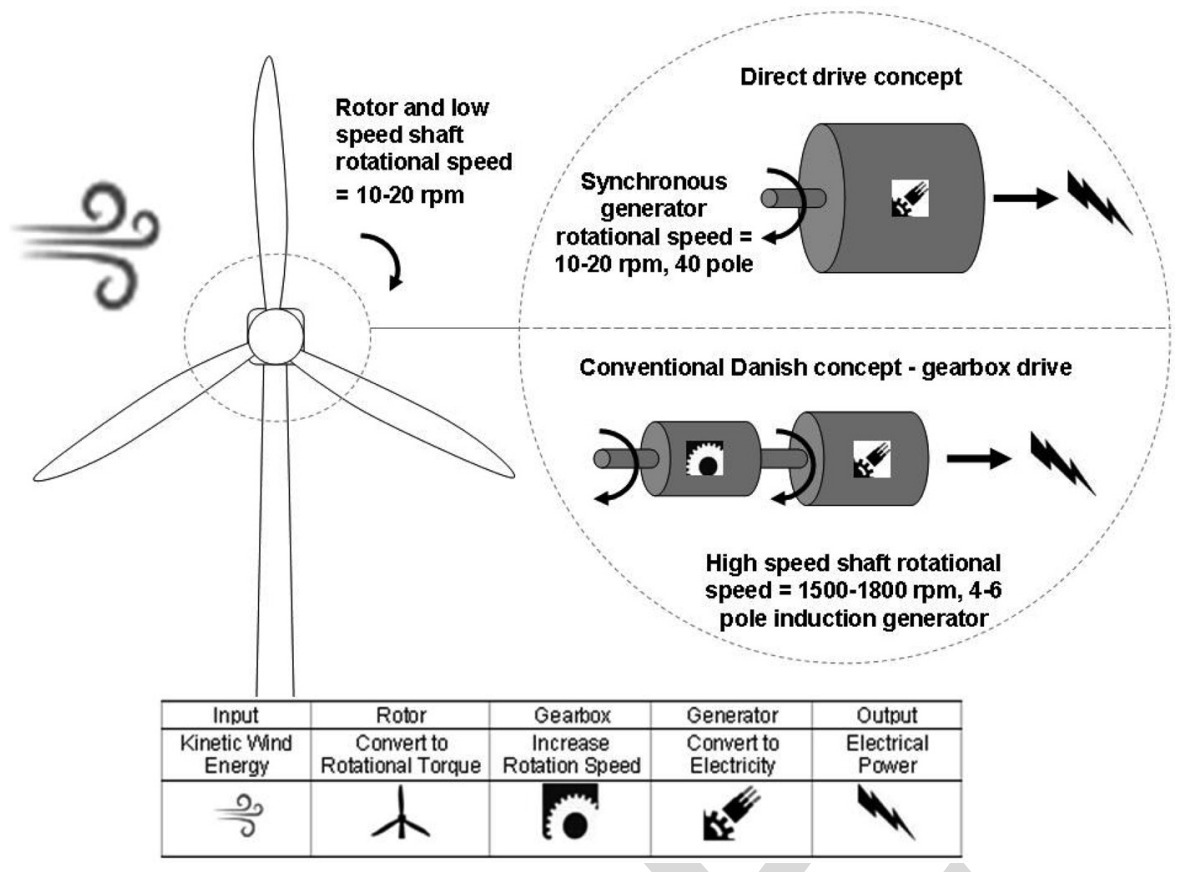

Fig. 2. Process diagram for gearbox-driven and direct drive wind turbines.

synchronous generators and tend to have fewer electrical faults. However, due to the low rotational speed of the wind turbine rotor, a gearbox has to be used to increase the rotation from tens of revolutions per minute at the gearbox input to thousands at the output. The primary reason for this is the low number of induction generator poles.

The older Danish concept WTs that operated at fixed speed employed squirrel cage induction generators; however, newer variable speed technology has resulted in a switch to doubly fed induction generators (DFIG), which are now the dominant wind turbine generator configuration. The reason for the dominance of this configuration is that it represents a good compromise between economy and performance. It is relatively economic because it has only a partial electronic converter rated at $\sim 30 \%$ of the generator output [6], not a full converter.

\section{B. Direct Drive Concept}

In a direct drive WT, the main rotor is coupled to the generator input shaft, eliminating the need for a gearbox in the design. In order to generate power at such a low rotation speed, the generator has to have many pole pairs, and usually a synchronous generator is employed. This implies much greater dimensions and weight as compared with an induction generator. In addition, a fully rated electronic power converter is required, which increases the cost of the system.

\section{Types of Comparison}

There are several examples in the published literature where a comparison is made between the two concepts. For example, Tavner et al. [3] focused on how the configuration of the WT generator and converter in different design concepts affected overall WT reliability. The data utilized by the authors had enough detail to enable a direct reliability comparison of three WT concepts: fixed speed with gearbox, variable speed with gearbox, and variable speed direct drive (no gearbox: synchronous generator). The main conclusion was that direct drive systems are less reliable than models with a gearbox because the potential increase in reliability due to elimination of gearbox failures is cancelled out by increased generator, inverter, and electrical system failures.

Interestingly, the authors recognized that overall availability would also be affected by component repair times: In this sense direct drive systems may have an advantage, as mean time to repair (MTTR) for a gearbox is likely to be very much more than MTTR for an electronics subassembly. As yet, no other research has addressed this operational comparison of the two concepts.

Echavarria et al. [4] analyzed a similar dataset, which provides some highly relevant information regarding the reliability of the two WT concepts. In particular, the data suggest that generator failures in direct drive WTs are roughly two times the gearbox-driven equivalent ( 0.22 failures per annum compared with 0.12 suggested by Tavner $e t$ al. [7]). Similarly, power electronics failures in direct drive synchronous machines are quantified as 1.03 failures per annum compared to 0.661 suggested in [7] for the induction machine equivalent.

Polinder et al. [6] examine direct drive and gearbox-driven WT concepts from the viewpoint of design and economic performance. The authors define a typical Danish concept WT with a three-stage gearbox (3GDFIG) and a direct drive machine coupled to a synchronous generator (DDSG). Three other concepts are also defined (DFIG with a single-stage gearbox, permanent magnet direct drive, and permanent magnet single-stage gearbox) but these are not considered in this paper due to the fact that they are not currently deployed in significant numbers. 


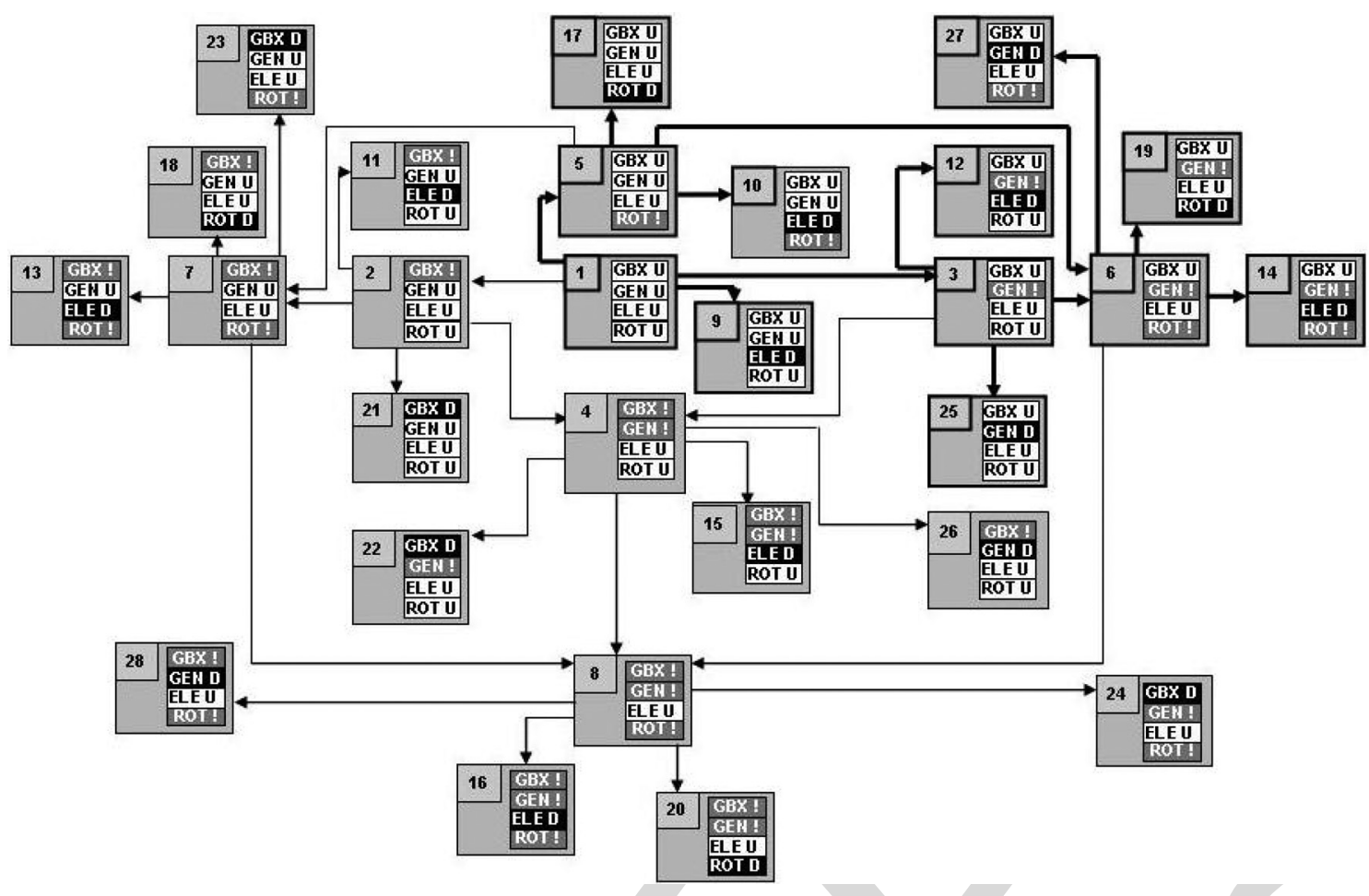

Fig. 3. Markov chain of key wind turbine components. Bold arrows and boxes indicate direct drive system.

The authors again highlight the need for further work to better understand the reliability and availability benefits of adopting different WT design concepts-a requirement which this paper aims to meet.

\section{MOdELING OF Wind TURBINE CONCEPTS}

\section{A. Physical Modeling of Wind Turbine Components}

In order to build an accurate operational model, the key physical components of the WT must be identified and a suitable mathematical representation decided upon. It was reported in [5] that using a combination of failure rate data, downtime estimates, and expert opinion, the key components of a gearboxdriven WT could be identified as follows:

1) gearbox (GBX);

2) generator (GEN);

3) rotor blades (ROT); and

4) inverter, electronics, and control (ELE).

In terms of the mathematical representation, a Markov chain solved via Monte Carlo simulation (MCS) was identified in previous studies as a suitable model framework [5]. The Markov chain representation has been very successfully applied to power systems infrastructure deterioration and failure modeling, including wind turbines [8], [9]. The main problem with these analytically solved models is that the introduction of constraints, such as weather-constrained maintenance, makes obtaining a solution rather difficult. Although not computationally efficient, MCS methods overcome this difficulty and have been applied to similar problems in the past [10], [11]. Since the problem considered is essentially a planning problem, the time required to get the solution is of little importance.
It has been assumed that three states are sufficient to capture the deterioration and failure processes of the GBX, GEN, and ROT. ELE failures are assumed to be instantaneous and, therefore, require only binary representation. When all four components are modeled in a single Markov state-space, the total number of states is 54 . This is cut down to 28 by assuming that degradation and failure events of different WT components cannot happen concurrently. Furthermore, for a GBX, GEN, or ROT failure to occur, the system must transit through the deteriorated (intermediate) state before outright failure.

The possible Markov states and transitions for the overall WT system are visualized in Fig. 3. The three possible deterioration levels are indicated as fully up (U), deteriorated (!), and down (D).

All 28 states and transitions are possible for the case of gearbox-driven WTs. The obvious physical difference when modeling a direct drive WT is that there are no gearbox states. Thus, the bold arrows in Fig. 3 refer to the transitions and states that represent direct drive WTs, as a 12-state subset.

The arrows in Fig. 3 represent transition probabilities (e.g., probability of transition from state $a$ to state $b$ is $p_{a, b}$ ), whose magnitude must be estimated. These probabilities depend only on the current state of the system $(s)$ at current time $t_{k}$. Equation 1 expresses this "memory-less" property of a Markov chain

$$
p_{a, b}=p\left(s_{b}, t_{k+1} \mid s_{a}, t_{k}\right) \quad k=1,2,3, \ldots
$$

Furthermore, the transition probabilities are constant in time: 186 This is the "time-stationary" property. The magnitude of all 187 transition probabilities from one state $(a)$ to all others in the 188 


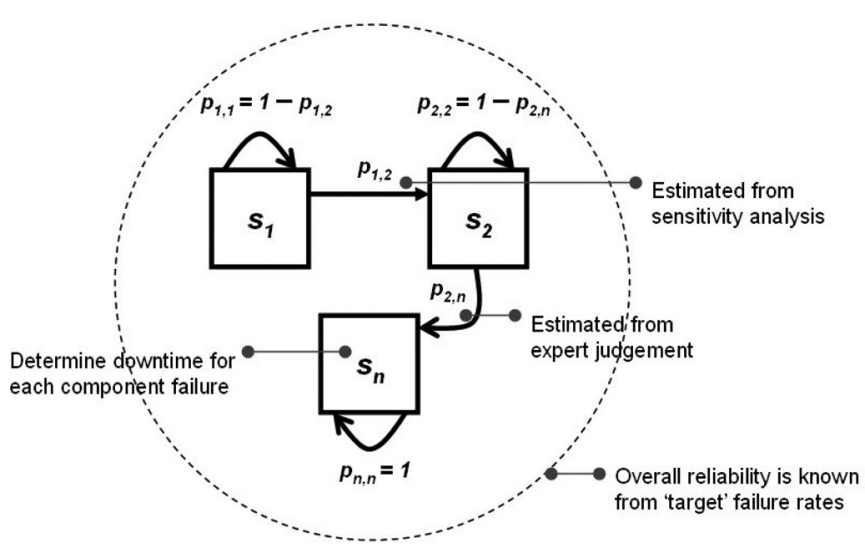

Fig. 4. Parameter estimation for Markov chain.

system must sum to unity. This is shown in (2)

$$
\sum_{b} p_{a, b}=1 \quad a=1 \ldots n
$$

where $n$ is the total number of system states. For convenience, the transition probabilities for the whole system are expressed in a transition probability matrix (TPM). For the case of the system in Fig. 3, the TPM is shown in (3). Note that only the possible transitions (indicated in Fig. 3. with arrows) need to be estimated —all other probabilities are equal to zero

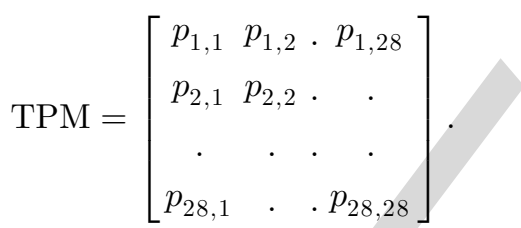

The TPM values are estimated based on the partial information available, as illustrated in Fig. 4. A good estimate of the overall reliability ("target" failure rate) is known from the work of Tavner et al. [7].

Similarly, downtime estimates can be made for the outage of the key components [5]. The probability of an outright failure in a deteriorated condition $\left(p_{2, n}\right)$ can be estimated based on expert opinion of times to failure. The remaining parameters can then be estimated by conducting sensitivity analyses (previously reported in [5]).

\section{B. Data for Physical Model}

The study of Tavner et al. [7] provided estimates of component failure rates based on populations of Danish and German WTs. The German population was larger (over 4,000 machines) and the population consisted of more modern WTs. Therefore, the German figures are used to fit the gearbox-drive WT physical model.

On the other hand, Echavarria et al. [4] suggest modifications to the GEN and ELE failure rates for direct drive machines. Taking this into account, the target failure rates for both WT concepts can be visualized in Fig. 5 .

Downtimes for the failure types are as follows: GBX-30 days, GEN-21 days, ELE-1 day, and ROT - 30 days. They are based on domain knowledge elicited in [5]. Using this

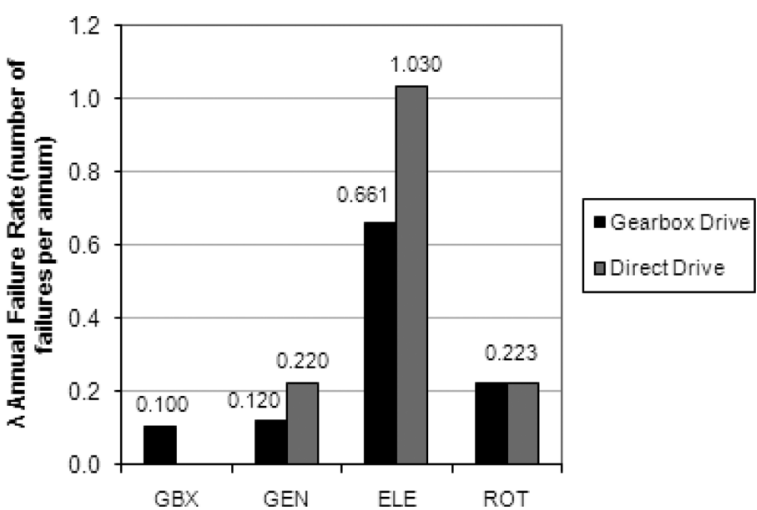

Fig. 5. Reliability for gearbox-driven and direct drive wind turbines.

information, the TPM parameters were estimated based on the 220 iterative procedure devised in [5]. The procedure is based on 221 sensitivity analysis estimation of the unknown parameter $p_{1,2} 222$ (see Fig. 4).

The Markov chain has been defined for both gearbox-driven 224 and direct drive concepts. In the following sections, other as- 225 pects of operational modeling - which are common to both 226 concepts-are discussed.

\section{Energy Yield Modeling}

There are two main components to the energy yield model. 229 These are the wind speed model and the power curve model. The 230 wind speed (WS) model previously used by the authors [5] was 231 based on a single parameter autoregressive process, or AR(1). 232 This is displayed in (4), where $\mu$ is the mean of a wind speed 233 time series, $\phi$ is the autoregressive parameter and the process is 234 driven by a Gaussian white noise function $\varepsilon_{t}$.

$$
\mathrm{WS}_{t}-\mu=\phi\left(\mathrm{WS}_{t-1}-\mu\right)+\varepsilon_{t} .
$$

The dataset used to fit the model was sourced from a su- 236 pervisory control and data acquisition (SCADA) system of a 237 U.K. wind farm. Estimation of $\phi$ and $\varepsilon_{t}$ was achieved by lin- 238 ear least squares, while classification of the model was based 239 on inspection of the autocorrelation and partial-autocorrelation 240 functions.

The power curve model is based on a manufacturers' datasheet for a 2 MW WT [12], which is sampled and the theoretical equation for the power $(P)$ in the wind $(5)$ is matched to the data samples by modeling the coefficient of performance $C_{p}$

$$
P=\frac{1}{2} \rho \pi r^{2} v^{3}\left(\times C_{p}\right) .
$$

In (5), $\rho$ is air density $\left(\mathrm{kg} / \mathrm{m}^{3}\right), r$ is the rotor radius (m), and $v \quad 247$ is air velocity through the WT rotor $(\mathrm{m} / \mathrm{s})$. The re-created power 248 curve is shown in Fig. 6 and has cut in, rated, and cut out wind 249 speeds of 4,14 , and $25 \mathrm{~m} / \mathrm{s}$, respectively. It is assumed that both 250 WT concepts adhere to the same power curve. 


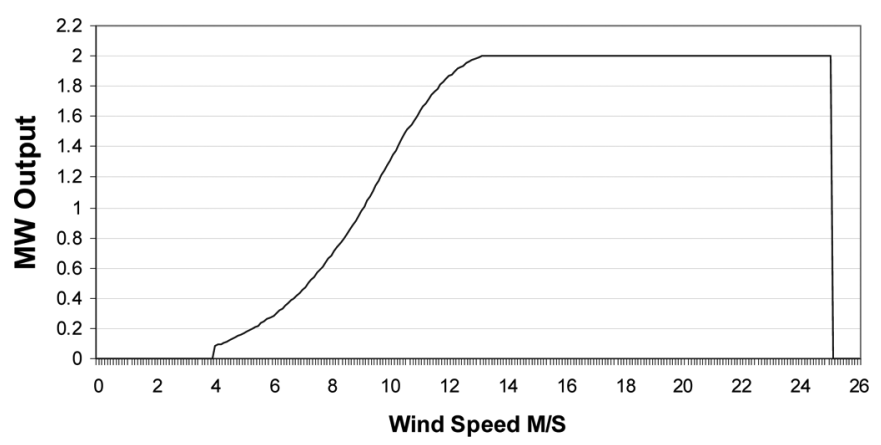

Fig. 6. Power curve for $2 \mathrm{MW}$ wind turbine [12].

\section{Maintenance Modeling}

It is assumed that a six-monthly periodic maintenance plan is adopted for both WT concepts. The assumptions in the maintenance model are that maintenance actions restore the WT to the fully up state (state 1 in Fig. 3) and that each maintenance visit involves a one-day outage. The model can easily accommodate condition-based maintenance (CBM), but since maintenance paradigms are not the focus of this paper, this possibility is neglected.

If a component failure occurs, a maintenance team is dispatched immediately. There is a probability that a component replacement is necessary (replacement factor $\beta=0.6$ ) or that it can be repaired $(1-\beta=0.4)$. This is based on an analysis by Ribrant and Bertling [13] who highlighted that around $60 \%$ of gearbox failures require a replacement rather than a repair action. Similar figures have not been published for the other WT components; therefore, due to the lack of data, they are assumed to have the same probabilities of repair and replacement as the gearbox.

If the component can be repaired, it is restored instantaneously to a functional state. If a replacement is required, downtime lasts as follows: GBX-30 days, GEN-21 days, ELE-1 day, and ROT - 30 days. This is based on the experience of a wind farm operator. Furthermore, maintenance actions are constrained by wind speed as in [5]. This means that nacelle-related replacements need wind speed conditions of less than $10 \mathrm{~m} / \mathrm{s}$, while rotor maintenance cannot be conducted in wind speeds over $7 \mathrm{~m} / \mathrm{s}$.

\section{E. Costs and Revenue}

It is of interest to compare the economic merits of the two WT configurations. Therefore, a cost model has been built which generates revenue from energy yield and incurs maintenance and replacement costs.

Polinder et al. provided costs for gearbox-driven and direct drive wind turbine components rated at $3 \mathrm{MW}$ [6]. Figures can be derived for $2 \mathrm{MW}$ machines of both types assuming that the cost varies linearly with the rating. These costs are provided in Table I. The rotor cost was not provided in [6] and so the value derived previously by the authors of this paper is adopted [5]. In the case of a component replacement, the full cost in Table I
TABLE I

COMPONENT COSTS FOR WIND TURBINE CONCEPTS

\begin{tabular}{|c|c|c|}
\hline Component & \multicolumn{2}{|c|}{ Cost $£$} \\
\hline GBX & 121,733 & N/A \\
\hline GEN & 177,066 & 313,740 \\
\hline ROT & 210,000 & 210,000 \\
\hline ELE & 22,133 & 66,400 \\
\hline
\end{tabular}

is incurred. In the case of a repair, it is assumed that only $10 \%$ of this cost is incurred (repair cost factor $\alpha=0.1$ ).

Besides the costs of the components themselves, the cost of labor and equipment hire has been included. Andrawus [14] showed that skilled labor for WT repairs costs around $£ 50 / \mathrm{h}$. It has been assumed that three crew working an $8 \mathrm{~h}$ shift constitute one maintenance action. Therefore, the cost of labor $\left(C_{\mathrm{LAB}}\right)$ is $£ 1200$ per action. Similarly, hire rates for telescopic cranes $\left(C_{\mathrm{EQ}}\right)$ needed to perform nacelle component lifting operations have been quantified by industry sources [15] as $£ 1500$ per week. Lost revenue due to downtime is also taken into account $\left(R_{\mathrm{LOST}}\right)$ - this is wind speed-dependent. These costs are combined with the component costs (see Table I) to calculate replacement (6), repair, (7) and O\&M cost (8)

$$
\begin{aligned}
C_{\text {replace }} & =\beta \lambda\left(C_{\mathrm{CAP}}+C_{\mathrm{LAB}}+C_{\mathrm{EQ}}+R_{\mathrm{LOST}}\right) \\
C_{\text {repair }} & =(1-\beta) \lambda \times\left(\alpha C_{\mathrm{CAP}}+C_{\mathrm{LAB}}+C_{\mathrm{EQ}}+R_{\mathrm{LOST}}\right) \\
C_{\mathrm{O} \& \mathrm{M}} & =C_{\text {replace }}+C_{\text {repair }} .
\end{aligned}
$$

The revenue model for the WT is based on the energy yield in 306 each one-day simulation interval. Using equations (4) and (5), 307 this energy yield $Y$ can be calculated as the power (see Fig. 6) 308 multiplied by a time interval $\Delta t$. The energy yielded in a year is 309 then calculated by summing the output over all individual days 310 in the year.

The revenue stream $R$ can then be calculated by applying equation (9). MP represents the market price for electricity and renewable obligation certificates (ROCs). For this paper, $\mathrm{MP}_{\text {elec }}$ and $\mathrm{MP}_{\mathrm{ROC}}$ are set to $£ 36$ and $£ 40$ per MWh, respectively. Although in reality, electricity and ROC prices fluctuate, the annual mean is adequately represented by the figures presented as

$$
R=Y\left(\mathrm{MP}_{\text {elec }}+\mathrm{MP}_{\mathrm{ROC}}\right)-C_{\mathrm{O} \& \mathrm{M}} .
$$

It is important to note that any differences in yield between the two WT concepts will be related to the reliability and downtime (see Fig. 5 and Section III-D) of the two WT concepts, rather than to the differences in the electrical design. This is because the same power curve (Fig. 6) has been used for both WT concepts.

Polinder et al. showed that the theoretical difference in yield between a $3 \mathrm{MW}$ direct drive machine (DDSG) and a typical 3 MW DFIG (DFIG3G) is $+150 \mathrm{MWh}$ [6], if the detail of the electrical machine design is taken into account. Assuming this difference scales linearly with WT rating, it means that for the $2 \mathrm{MW}$ machines considered in this paper, the direct drive machine yields roughly $100 \mathrm{MWh}$ more per annum than the 


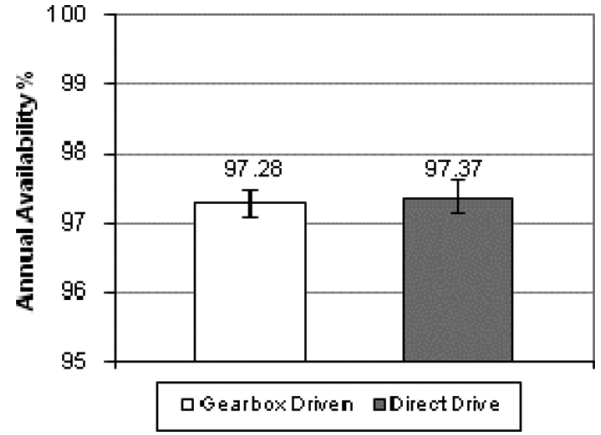

Fig. 7. Availability comparison of wind turbine concepts.

DFIG. Applying (9) and neglecting the O\&M cost, this translates to $£ 7600$ more revenue per annum for the direct drive machine. Therefore, the annual revenue for the direct drive machine has been boosted by $£ 7600$ per annum in the studies that follow.

\section{F. Program Operation}

The models outlined in this section were coded in FORTRAN 95, with the SCADA database interface for the wind speed model written using f90SQL [16]. The statistical programming language $\mathrm{R}$ was used to fit the wind speed model defined in (4). The resultant capacity factor of the wind turbine based on the simulated wind speed and power curve is just under $30 \%$.

The confidence limit $L$ of the simulation results can be measured by applying (10). Taking the Student- $t$ distribution, and setting the level of confidence to $95 \%$, it means that $L$ can be specified, provided that the number of samples $(N)$ and standard deviation $(\sigma)$ of the quantity are known. $L$ is shown in the results as confidence bands that specify the accuracy of the results

$$
L= \pm \frac{2.045 \times \sigma}{\sqrt{N}} .
$$

\section{A. Operational Comparison of Concepts}

Two comparisons are made in order to benchmark the operational merits of the two WT concepts: a technical comparison and an economic comparison. The first result in Fig. 7 compares the overall availability of the two concepts.

It can be seen that despite removing the gearbox from the design, the direct drive concept has similar overall availability to the gearbox-driven machine. Although the availability is marginally better for the case of the direct drive machine, the confidence limits show that this technical benefit is uncertain. It should be noted that grid availability is not included in this paper.

The second result, displayed in Fig. 8, shows the revenue generated (9) for both concepts. This shows that the gearboxdriven design has a much larger economic benefit than the direct drive concept.

The contribution to the revenue of increased energy yield due to avoidance of downtime is negligible in the case of Fig. 8 (direct drive machine avoids loss of $\sim 6.35 \mathrm{MWh}$ more energy

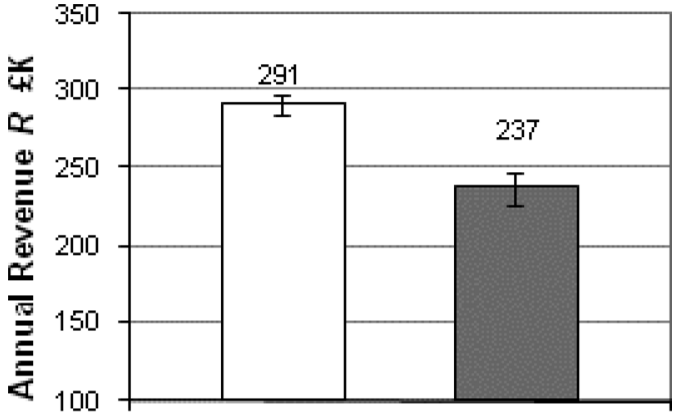

口b̀earboxDriwen aDireot Driwe

Fig. 8. Economic comparison of wind turbine concepts.

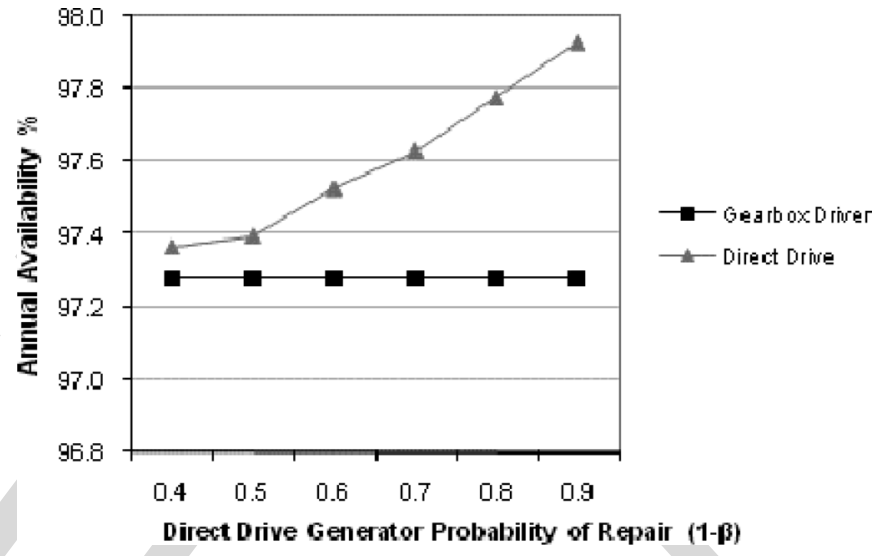

Fig. 9. Availability improvement of direct drive wind turbine as a function of generator reparability.

than gearbox-driven, economic benefit $=£ 482$ per annum). 368 Therefore, the large disparity in revenue $(\sim £ 44000$ per annum) 369 must be due to incurred repair and replacement costs. The large 370 increase in cost and failure rate for the generator in particular 371 (see Table I and Fig. 5) appears to economically handicap the 372 direct drive concept.

\section{B. Operational Impact of Generator Reparability}

One possible explanation of the superior economic performance of the gearbox-drive concept is that a replacement factor $(\beta)$ of 0.6 per failure (see Section III-D) may represent a pessimistic view of the "reparability" of a WT synchronous generator. Indeed, it has been reported elsewhere [3] that the increase in generator failure rate for the direct drive concept is related to electrical failures rather than mechanical failures. Electrical faults will be less likely to involve a complete component replacement; therefore, the robustness of the conclusion drawn from Fig. 8 is tested by modeling different levels of reparability for the direct drive generator.

The replacement factor $\beta$ was reduced from the base value of 386 $0.6-0.1$, as shown in Fig. 9. This figure shows that the opera- 387 tional availability of the direct drive concept WT can be signif- 388 icantly higher than the gearbox-driven WT, if a high proportion 389 of synchronous generator failures are minor electrical failures 390 rather than severe mechanical failures (e.g., bearing problems). 391 


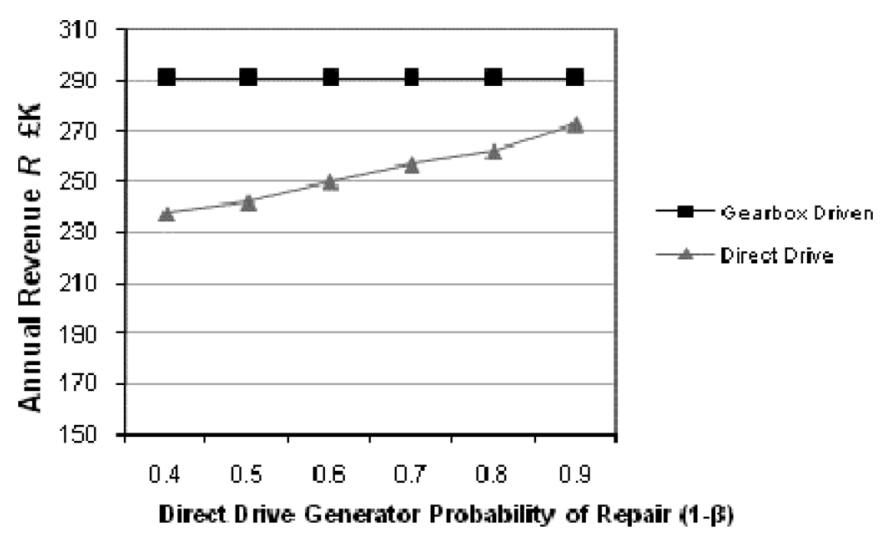

Fig. 10. Revenue increase of direct drive wind turbine as a function of generator reparability.



Fig. 11. Revenue increase of direct drive wind turbine as a function of component cost reduction.

The economic impact of this variation is illustrated in Fig. 10. This figure shows that even for an optimistic scenario, the annual revenue of the direct drive WT is still $\sim £ 20000$ less than the equivalent gearbox-driven WT. This aspect of WT component reparability has not received much attention in the literature, but Fig. 10 in particular shows that it is a significant factor when conducting operational modeling of WT concepts. More studies of the type conducted by Ribrant and Bertling [13] will be needed in order to better understand the reparability of different WT components and their effect on operational metrics such as availability and revenue. Analysis of WT failures in the context of repairs and replacements along with their probabilities and costs are crucial for a deep understanding of wind farm operational issues.

\section{Operational Impact of Component Cost Reduction}

In the WT marketplace, there is currently one company that builds $2 \mathrm{MW}$ direct drive machines on an industrial scale [17]; however, other large WT manufacturers have identified direct drive machines as an avenue for future production [18]. With more players in the market, it may be possible to significantly reduce the direct drive component cost through a refinement of mass production manufacturing processes. Therefore, it is of interest to review the effect on the economic case for direct drive machines if component costs are lowered. Such a review is provided in Fig. 11, where the GEN and ELE component costs are reduced in $10 \%$ steps to $50 \%$ of the original Table I values.
The final result shows that if substantial cost reductions in direct drive technology are achieved in the future, this measure may be enough to make the technology cost-competitive with DFIGs. However, very large cost reductions of $50 \%+$ will be required. At current prices, the economic argument for a switch to direct drive technology, for the onshore conditions evaluated, appears to be weak.

\section{CONCLUSION}

An operational comparison of direct drive and gearbox-driven wind turbines has been presented in this paper. The results suggest that there may be a technical advantage in deploying direct drive machines over more established gearbox-driven designs (see Fig. 9). In all cases, the economic analysis shows that gearbox-driven machines are still preferable, unless manufacturing costs of direct drive technology can be significantly reduced (see Fig. 11).

There are some issues that need to be better understood in order to make more precise comparisons of these technologies. One is that the repair probability of the components needs to be investigated, in a manner similar to the one presented in [13] but for all WT components. The failure rate increase for a synchronous generator relative to an induction generator (reported in [3], [4]) will be made up mainly of electrical-related failures rather than mechanical failures. It would be interesting to see what proportion of direct drive WT generator failures are low downtime (e.g., 1-3 days) as opposed to a mechanical failure of a rotating component, which in some cases could take as long as 60 days to replace [14]. Such an analysis would aid understanding of WT failure modes and make operational comparisons more accurate.

This study was carried out for fairly typical onshore conditions, but the conclusions may be linked to the site conditions. Direct drive machines are perceived by some manufacturers as primarily an offshore technology [18]. By modeling the offshore wind resource, logistics, increased downtimes, and offshore access constraints, it may be possible to determine if direct drive machines would become more economically attractive in offshore conditions than the analysis presented in this paper shows. The conclusions of the results in this paper and any further analysis as described will be of value to both manufacturers and operators of wind turbines.

\section{ACKNOWLEDGMENT}

The authors would like to thank Y. Patel of Scottish Power/Iberdrola and M. Smith of Macom Technologies for their valuable input to this paper. The authors would also like to thank Dr. D. Hill and the IEEE reviewer for their valuable comments.

\section{REFERENCES}

[1] Scottish Power/Iberdrola press release (2008, Nov. 9). "Scottish Power Renewables Windfarm Pushes Britain Past 3GW Wind Energy Landmark," [Online]. Available: http://www.(scottishpower.com/ PressReleases_1774.htm)

[2] British Wind Energy Association (2008, Nov. 15). "Operational wind farms," [Online]. Available: http://www.(bwea.com/ukwed/ operational.asp) 
[3] P. J. Tavner, G. J. W. V. Bussel, and F. Spinato, "Machine and converter reliabilities in wind turbines," in Proc. 3rd Power Electron. Mach. Drives Conf. (PEMD 2006), Cork, Ireland, Mar., pp. 127-130.

[4] E. Echavarria, B. Hahn, G. J. W. van Bussel, and T. Tomiyama, "Reliability of wind turbine technology through time," Trans. ASME (J. Sol. Eng.), vol. 130, no. 3, pp. 0310051-0310058, Aug. 2008.

[5] D. McMillan and G. W. Ault, "Condition monitoring benefit for wind turbines: Sensitivity to operational parameters," IET Renewable Power Generation, vol. 2, no. 1, pp. 60-72, Mar. 2008.

[6] H. Polinder, F. F. A. Van Der Pijl, G. de Vilder, and P. J. Tavner, "Comparison of direct-drive and geared generator concepts for wind turbines,' IEEE Trans. Energy Convers., vol. 21, no. 3, pp. 725-733, Sep. 2006.

[7] P. J. Tavner, J. Xiang, and F. Spinato, "Reliability analysis for wind turbines," Wind Energy, vol. 10, no. 1, pp. 1-18, Jun. 2007.

[8] R. P. Hoskins, G. Strbac, and A. T. Brint, "Modelling the degradation of condition indices," IEE Proc.- Generation, Transmiss., Distrib., vol. 146 , no. 4, pp. 386-392, Jul. 2002.

[9] F. C. Sayas and R. N. Allan, "Generation availability assessment of wind farms," IEE Proc.- Generation, Transmiss., Distrib., vol. 143, no. 5, pp. 507-518, Sep. 1996.

[10] M. Marseguerra, E. Zio, and L. Podofillini, "Condition-based maintenance optimization by means of genetic algorithms and Monte Carlo simulation,' Rel. Eng. Syst. Safety, vol. 77, no. 2, pp. 151-165, Jul. 2002.

11] N. B. Negra, O. Holmstrom, B. Bak-Jensen, and P. Sorensen, "Aspects of relevance in offshore wind farm reliability assessment," IEEE Trans. Energy Convers., vol. 22, no. 1, pp. 159-166, Mar. 2007.

[12] Vestas (2008, May 1). "V80-2.0 MW Versatile Megawattage," Manufacturers Data Sheet. [Online]. Available: http://www.vestas.com/en/windpower-solutions/wind-turbines/2.0-mw.aspx

[13] J. Ribrant and L. Bertling, "Survey of failures in wind power systems with focus on Swedish wind power plants during 1997-2005," IEEE Trans. Energy Convers., vol. 22, no. 1, pp. 167-173, Mar. 2007.

14] J. A. Andrawus, J. Watson, M. Kishk, and A. Adam, "The selection of a suitable maintenance strategy for wind turbines," Wind Eng., vol. 30, no. 6, pp. 471-486, Dec. 2006.

[15] Anon "Expansion based on rental," Cranes Access, vol. 8, no. 7, pp. 24 25, Oct. 2006

[16] F90SQL, [Online]. Available: http://www.(http://www.canaimasoft.com/ f90sql/)

[17] Enercon GmbH E-82 2008, Dec. 1). [Online]. Available: http:// www.(http://www.enercon.de/en/ home.htm)

18] K. Larsen, "Making wind more efficient," Renew. Energy Focus, pp. 4042, Nov./Dec. 2008

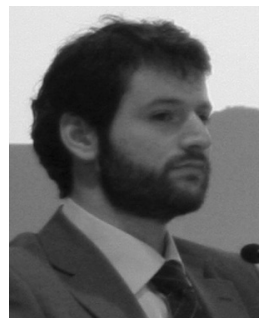

David McMillan (M'06) received the B.Eng. de- 515 gree in electronics and electrical engineering from the 516 University of Glasgow, Glasgow, Scotland, U.K., in 517 2002, and the M.Sc. and Ph.D. degrees from the Uni- 518 versity of Strathclyde, Glasgow, in 2005 and 2008, 519 respectively.

From 2002 to 2004, he was a Manufacturing En- 521 gineer with Methode Electronics, Burnley. He is cur- 522 rently a Research Fellow at the Institute for Energy 523 and Environment, University of Strathclyde. His re- 524 search interests include techno-economic analysis of 525 energy generation and infrastructure and storage technologies.

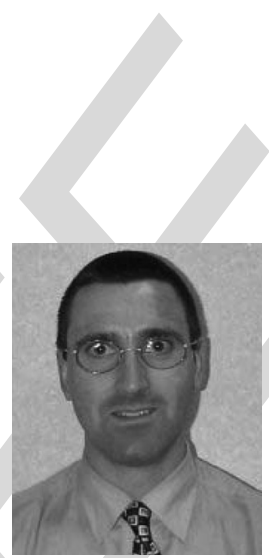

Graham W. Ault (S'96-M'00) received the B.Eng. degree in electrical and mechanical engineering, and 529 the $\mathrm{Ph} . \mathrm{D}$. degree in electrical power systems from the 530 University of Strathclyde, Glasgow, Scotland, U.K., 531 in 1993 and 2000, respectively.

He is currently a Reader with the University of 533 Strathclyde, where he has been engaged in several 534 aspects of distributed and renewable generation, asset 535 management, and power system planning and devel- 536 opment. He has been actively involved in national and 537 international initiatives to advance the development 538 of the renewable energy industry through the Institution of Engineering and 539 Technology, IEEE, Congrès International des Réseaux Electriques de Distribu- 540 tion or International Conference on Electricity Distribution, and International 541 Energy Agency. 
Q1: Author: Please check the edit changes in this sentence for correctness.

Q2. Author: Please check the edit changes in this sentence for correctness.

Q3. Author: Please provide year in Ref. [16].

Q4. Author: Please provide complete bibliographic details in Ref. [18]. 